\title{
The Use of Different Data Sets in 3D Modelling
}

\author{
Ahmed M. Hamruni \\ Civil Engineering Department, Faculty of Engineering, Almergib University, Alkhoms, Libya
}

\begin{abstract}
The needs for photo-realistic modelling of the complete details, and geometrically accurate 3D models are growing rapidly in several fields, especially in engineering and cultural heritage documentation. This paper explored the geometry of the Pictometry images (vertical and oblique) and the possibility of using this imagery in 3D modelling to produce photo-realistic and accurate models. In addition, merging terrestrial imagery with Pictometry imagery to get more ground level details has been investigated. All work has been carried out using the available software packages at the IESSG (Institute of Engineering Surveying and Space Geodesy) and using data provided by Blom Aerofilms Ltd. The results of the aerial triangulation of different Pictometry blocks showed that high quality image measurements have been achieved for all the image blocks. Extraction of 3D geometry for all buildings in the study area has been performed using both vertical Pictometry imagery and UltraCamD imagery. The successful combining of vertical and oblique Pictometry images provided an excellent opportunity to produce an efficient method of high quality urban model texturing. The integration of terrestrial images of building facades (whose texture needs enhancement) with the combined aerial imagery block has been successfully and automatically performed.
\end{abstract}

Key words: Oblique, triangulation, 3D modelling, texturing, photorealism.

\section{Introduction}

\subsection{Background}

Site recording and modelling has been an important topic in photogrammetry from its very beginning in the middle of the 19th century. Since then technologies have changed several times fundamentally [1]. The recent rapid development of multisensor and multimedia technologies has made it possible to construct and visualise detailed 3D models of our built environment. For 3D city models, the most important features are buildings which have to be acquired in densely built-up areas, centres of cities and towns where very complex, highly irregular house and roof patterns are common. Fig. 1 shows some of the different roof patterns that are present in the study area.

\subsection{Importance of 3D Models}

In a steady shift from traditional 2D-GIS

Corresponding author: Ahmed Hamruni, assistant professor, research fields: 3D modelling, aerial triangulation and uses of aerial imagery in Engineering projects. Email: elhamrouni@hotmail.com.
(2D-geographic information system) toward 3D-GIS (3D-geographic information system), an increasing amount of accurate 3D city models have become required to be produced in a short period of time and provided widely on the market. The biggest advantage of the 3D model is its mobility and its convincing effect on users for future decision-making processes [2].

Digital 3D models have some advantages over traditional ways of geospatial data handling [3]:

(1) Due to its digital storage, models can be supplemented and reconstructed into different environments by means of importing and exporting tools;

(2) Realistic presentations of the model can be produced by using some kind of interactive animation and simulation environments (for example, VRML (virtual reality markup language) or X3D);

(3) Last but not least, digital models can always be updated and rebuilt individually or just be considered as a part of a complex model.

\subsection{Aim and Objectives}

The overall aim of this paper is to investigate the 


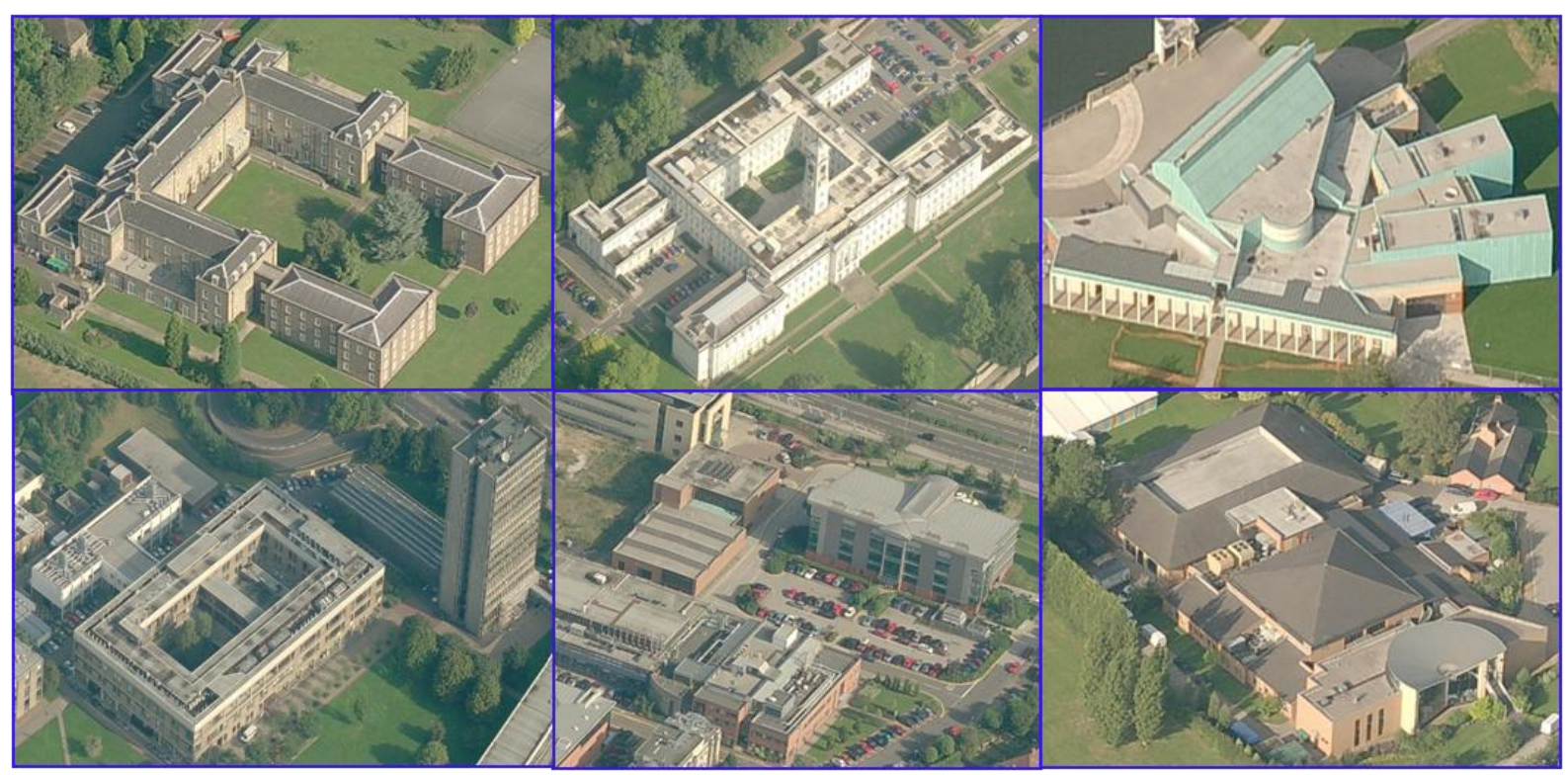

Fig. 1 Examples of different roof patterns in the study area.

geometric potential for using Pictometry imagery to provide 3D city modelling and texturing. This aim will be assessed through investigating the following objectives:

(1) Assessment of the images;

(2) Benefits in combining Pictometry imagery with UltraCamD images;

(3) Investigating the geometric quality of feature extraction;

(4) Assessment of 3D geometry of all buildings extracted using both photogrammetric systems: Pictometry and UltraCamD;

(5) Investigation into the quality of texturing the 3D models using vertical, oblique and combined blocks of both camera systems.

\section{Test Site and Data Sets}

\subsection{Test Site}

Images were available covering the University of Nottingham Campus with both Pictometry and the UltraCamD images and formed an ideal test site for the research described. Ground coordinated points have been established and formed the basic ground control for the Pictometry images and UltraCamD images. A small area in the city centre of Nottingham will be used as a further application case study where only Pictometry images are available. GPS ground survey has been used to provide independent check points for the evaluation.

\subsection{Imagery}

The available data consists of a block of 86 UltraCamD images with a focal length of nominally $100 \mathrm{~mm}$, a pixel size of $0.009 \mathrm{~mm}$ flown at a height of approximately $500 \mathrm{~m}$ to give a GSD of approximately $6 \mathrm{~cm}$, with $60 \%$ forward overlap and 30\% lateral overlap. High quality in-flight GPS and IMU data was available. The Pictometry digital images cover approximately a $2 \mathrm{~km}^{2}$ region of the University of Nottingham main campus and about $0.5 \mathrm{~km}^{2}$ in the city centre area. The GSD for the oblique imagery is approximately $11-15 \mathrm{~cm}$ with the flying height between approximately $975 \mathrm{~m}$ and $1038 \mathrm{~m}$. The GSD for the vertical imagery is approximately $10-14 \mathrm{~cm}$. The pixel size is $0.009 \mathrm{~mm}$ with a nominal focal length for the vertical camera of $65 \mathrm{~mm}$ and the oblique cameras of $85 \mathrm{~mm}$. The forward overlap for the vertical images varies from $38 \%$ to $46 \%$ and the side lap from $25 \%$ to $36 \%$. The forward overlap of the oblique imagery is approximately from $21 \%$ to $47 \%$ 
and side lap from $23 \%$ to $45 \%$. The oblique images were taken at an inclination angle of about $50^{\circ}$ from multiple viewing directions. This makes the building facades in both study areas adequately visible. In-flight GPS and rotation information were available but the quality is not fully known.

\section{Trials, Results and Analysis}

\subsection{Observation Techniques}

A total number of 39 coordinated ground points were available. These points were collected using static GPS with an estimated accuracy of $5 \mathrm{~cm}$ which was used as the standard deviation of the ground control points in the triangulation. Blocks involving the UltraCamD and Pictometry images: The observation for the GCP (ground control point) both in the Pictometry and UltraCamD images was performed manually. Most of the GCPs were easily identifiable due to the good radiometric quality of both blocks. Some difficulties were encountered while measuring GCPs on Pictometry images due to the tilt and the difference in scale. For the combined Pictometry-UltraCamD triangulation most GCPs were identified in both blocks. The tie points for the UltraCamD block were automatically extracted using a cross correlation area based on matching technique available in LPS (Leica Photogrammetric Suite). Blunder and mismatched points were identified manually by the operator based on the image residuals and were excluded in an iterative process after rerunning the AT. Tie points for the oblique image block were manually observed (see below) and the ground control/check points were also the tie points between the blocks. Blocks involving vertical and oblique Pictometry images: Aerial triangulation for all Pictometry blocks was performed using LPS. The number of tie points in the combined Pictometry block (vertical and oblique) was 494: 293 points were generated automatically to tie the vertical images together and 201 points were generated manually to tie the oblique images together. This was necessary because the automatic generation of tie points did not work with the oblique images due to different illumination and significantly different viewing directions.

For all blocks, during the aerial triangulation computations a number of points were rejected due to large image or ground control residuals. With images with large tilts it is always difficult to produce initial values for the computation. The Pictometry images were provided with rotations that were used, with some modification, as initial values in many cases.

\subsection{Aerial Triangulation Results}

Aerial triangulation for all Pictometry blocks and for UltraCamD blocks was performed using LPS software package. Four solutions have been considered: "float solution", "constrained solution", "integrated sensor orientation solution" and finally "direct georeferencing or only in-flight GPS and IMU solution".

\subsubsection{UltraCamD Block Results}

For the block of UltraCamD images, there are 33 control points. Nine points were selected as ground control points and 24 as check control points for the first two AT trials, while all control points were used as check points for the third and fourth AT trials. The distribution of the tie points and control/check points is shown in Fig. 2 as well as the images footprint and the camera $\mathrm{X}$-axis.

The AT results of the four solutions are shown in Table 1 . The results show very good image residuals and fit on the ground control points. The check points show more realistic values of what might be achievable for mapping. The GSD is about $5 \mathrm{~cm}$, the accuracy of CCPs in float solution reach $4 \mathrm{~cm}, 4 \mathrm{~cm}$ and $9 \mathrm{~cm}$ on the ground in $\mathrm{X}, \mathrm{Y}$ and $\mathrm{Z}$ components respectively. These are equivalent to $0.80,0.80$ and 1.8 GSD respectively. As the nominal vertical camera focal length is $100 \mathrm{~mm}$ and the average flying height is $500 \mathrm{~m}$, this corresponds to 8,8 , and $18 \mu \mathrm{m}$ in image scale which is $0.89,0.89$, and 2.0 pixels respectively. 


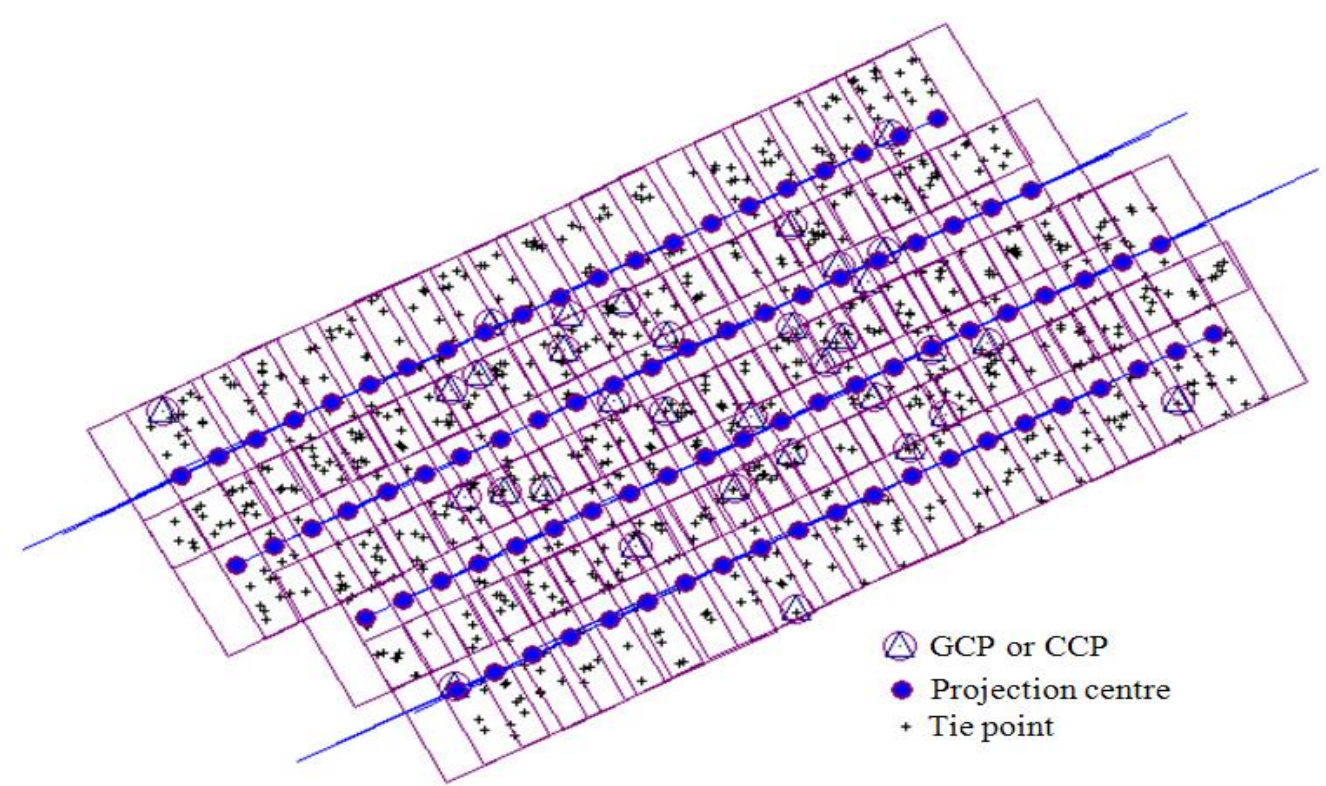

Fig. 2 UltraCamD images block showing images footprint, distribution of GCPs and tie points, and camera x-axis.

Table 1 Results of AT for UltraCamD images vertical block using four different solutions.

\begin{tabular}{|c|c|c|c|c|c|c|c|c|c|}
\hline Solution & & & bat & & rained & & rrated & & $G$ \\
\hline Additional $\mathrm{Pr}$ & neter & No & Yes & No & Yes & No & Yes & No & Yes \\
\hline $\begin{array}{l}\text { Total RMSE } \\
(\mu \mathrm{m})\end{array}$ & & 3.0 & 2.9 & 3.1 & 2.9 & 3.1 & 3.0 & 5.2 & 4.9 \\
\hline & $\begin{array}{l}X \\
(\mathrm{~m})\end{array}$ & $\begin{array}{l}0.062 \\
\text { (9) }\end{array}$ & $\begin{array}{l}0.059 \\
(9)\end{array}$ & $\begin{array}{l}0.069 \\
(9)\end{array}$ & $\begin{array}{l}0.059 \\
(9)\end{array}$ & - & - & - & - \\
\hline $\begin{array}{l}\text { GCPs RMS } \\
\text { (no.pts) }\end{array}$ & $\begin{array}{l}\mathrm{Y} \\
(\mathrm{m})\end{array}$ & $\begin{array}{l}0.068 \\
\text { (9) }\end{array}$ & $\begin{array}{l}0.055 \\
\text { (9) }\end{array}$ & $\begin{array}{l}0.056 \\
(9)\end{array}$ & $\begin{array}{l}0.043 \\
(9)\end{array}$ & - & - & - & - \\
\hline & $\begin{array}{l}\mathrm{Z} \\
(\mathrm{m})\end{array}$ & $\begin{array}{l}0.052 \\
\text { (9) }\end{array}$ & $\begin{array}{l}0.020 \\
(9)\end{array}$ & $\begin{array}{l}0.036 \\
(9)\end{array}$ & $\begin{array}{l}0.036 \\
(9)\end{array}$ & - & - & - & - \\
\hline & $\begin{array}{l}X \\
(\mathrm{~m})\end{array}$ & $\begin{array}{l}0.062 \\
(24)\end{array}$ & $\begin{array}{l}0.043 \\
(24)\end{array}$ & $\begin{array}{l}0.067 \\
(24)\end{array}$ & $\begin{array}{l}0.048 \\
(24)\end{array}$ & $\begin{array}{l}0.069 \\
(33)\end{array}$ & $\begin{array}{l}0.058 \\
(33)\end{array}$ & $\begin{array}{l}0.090 \\
(33)\end{array}$ & $\begin{array}{l}0.089 \\
(33)\end{array}$ \\
\hline CCPs RMS & $Y$ & 0.048 & 0.037 & 0.056 & 0.047 & 0.103 & 0.073 & 0.055 & 0.055 \\
\hline & Z & 0.118 & 0.089 & 0.107 & 0.109 & 0.105 & 0.096 & 0.123 & 0.102 \\
\hline & (m) & (24) & (24) & (24) & (24) & (33) & (33) & (33) & (33) \\
\hline
\end{tabular}

3.2.2 Vertical Pictometry Images Block

For the vertical Pictometry images block, the images are in the range of only 29 control points. Ten points were selected as ground control points and 19 as check control points for the first two AT trials while all control points were used as check points for the third and fourth AT trials. The distribution of the control/check points is shown in Fig. 3 as well as the images footprint. Although a great effort was made to ensure a good distribution of the control points throughout the block, the distribution of GCPs in the vertical Pictometry block was not ideal due to the lack of features that can be recognized or have enough texture and recognizable features in the upper left corner of the block as that area is covered completely by trees. However, since GPS/IMU data observations are available for each image, the weak control point configuration may not be a problem. The results (Table 2) show very good image residuals and fit on the ground control points. The check points show more realistic values of what might be achievable for mapping. When the GSD is $15 \mathrm{~cm}$, the accuracy of CCPs in float solution reach $9.4 \mathrm{~cm}, 8.2 \mathrm{~cm}$ and 29.5 $\mathrm{cm}$ on the ground in $\mathrm{X}, \mathrm{Y}$ and $\mathrm{Z}$ components. These are equivalent to $0.63,0.55$ and 2 GSD respectively. As the nominal vertical camera focal length is $65 \mathrm{~mm}$ 


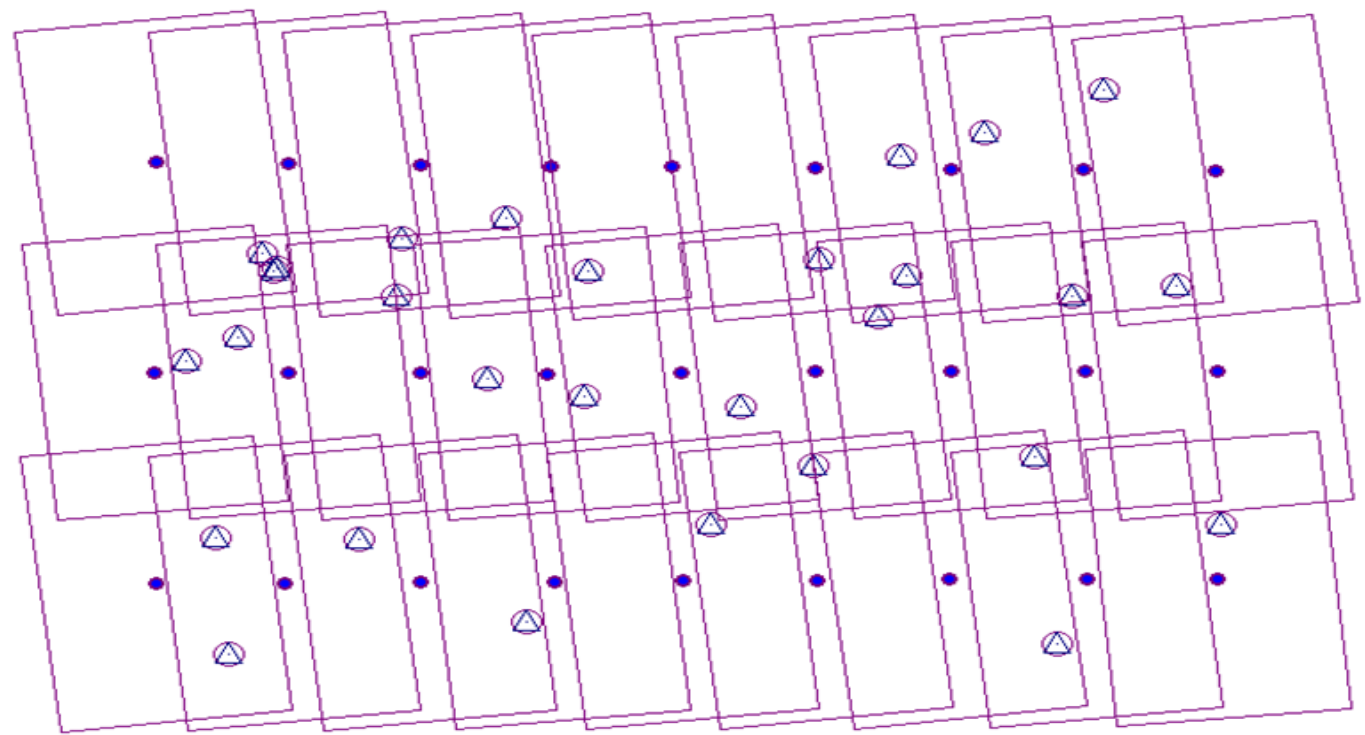

\section{GCP or CCP}

\section{Image projection centre}

Fig. 3 The vertical Pictometry images block showing the distribution of control points and images projection centres.

Table 2 Results of AT for the vertical Pictometry block using four different solutions.

\begin{tabular}{|c|c|c|c|c|c|c|c|c|c|}
\hline \multicolumn{2}{|l|}{ Solution } & \multicolumn{2}{|c|}{ Float } & \multicolumn{2}{|c|}{ Constrained } & \multicolumn{2}{|c|}{ Integrated } & \multicolumn{2}{|c|}{ DG } \\
\hline \multicolumn{2}{|c|}{ Additional Parameters } & No & Yes & No & Yes & No & Yes & No & Yes \\
\hline \multicolumn{2}{|c|}{ Total image RMSE $(\mu \mathrm{m})$} & 1.6 & 1.6 & 1.7 & 1.6 & 2.2 & 2.1 & 6.1 & 2.4 \\
\hline \multirow{3}{*}{$\begin{array}{l}\text { GCPs RMS } \\
\text { (no.pts) }\end{array}$} & $\mathrm{X}(\mathrm{m})$ & $\begin{array}{l}0.025 \\
(10)\end{array}$ & $\begin{array}{l}0.024 \\
(10)\end{array}$ & $\begin{array}{l}0.029 \\
(10)\end{array}$ & $\begin{array}{l}0.025 \\
(10)\end{array}$ & - & - & - & - \\
\hline & $\mathrm{Y}(\mathrm{m})$ & $\begin{array}{l}0.038 \\
(10)\end{array}$ & $\begin{array}{l}0.028 \\
(10)\end{array}$ & $\begin{array}{l}0.040 \\
(10)\end{array}$ & $\begin{array}{l}0.035 \\
(10)\end{array}$ & - & - & - & - \\
\hline & $\mathrm{Z}(\mathrm{m})$ & $\begin{array}{l}0.009 \\
(10)\end{array}$ & $\begin{array}{l}0.006 \\
(10)\end{array}$ & $\begin{array}{l}0.011 \\
(10)\end{array}$ & $\begin{array}{l}0.011 \\
(10)\end{array}$ & - & - & - & - \\
\hline \multirow{3}{*}{$\begin{array}{l}\text { CCPs RMS } \\
\text { (no. pts) }\end{array}$} & $\mathrm{X}(\mathrm{m})$ & $\begin{array}{l}0.094 \\
(19)\end{array}$ & $\begin{array}{l}0.089 \\
(19)\end{array}$ & $\begin{array}{l}0.086 \\
(19)\end{array}$ & $\begin{array}{l}0.080 \\
(19)\end{array}$ & $\begin{array}{l}0.283 \\
(29)\end{array}$ & $0.278(29)$ & $\begin{array}{l}0.208 \\
(26)\end{array}$ & $\begin{array}{l}0.204 \\
(26)\end{array}$ \\
\hline & $\mathrm{Y}(\mathrm{m})$ & $\begin{array}{l}0.082 \\
(19)\end{array}$ & $\begin{array}{l}0.076 \\
(19)\end{array}$ & $\begin{array}{l}0.077 \\
(19)\end{array}$ & $\begin{array}{l}0.071 \\
(19)\end{array}$ & $\begin{array}{l}0.447 \\
\text { (29) }\end{array}$ & $0.458(29)$ & $\begin{array}{l}0.552 \\
(26)\end{array}$ & $\begin{array}{l}0.460 \\
(26)\end{array}$ \\
\hline & $\mathrm{Z}(\mathrm{m})$ & $\begin{array}{l}0.295 \\
(19)\end{array}$ & $\begin{array}{l}0.163 \\
(19)\end{array}$ & $\begin{array}{l}0.157 \\
(19)\end{array}$ & $\begin{array}{l}0.147 \\
(19)\end{array}$ & $\begin{array}{l}0.921 \\
(29)\end{array}$ & $0.498(29)$ & $\begin{array}{l}0.644 \\
(26)\end{array}$ & $\begin{array}{l}0.629 \\
(26)\end{array}$ \\
\hline
\end{tabular}

and the average flying height is $1,000 \mathrm{~m}$, this corresponds to $6.1,5.3$, and $19 \mu \mathrm{m}$ in image scale which is $0.68,0.59$, and 2.1 pixels respectively.

Compared to the vertical Pictometry block, it is clear that the accuracy of UltraCamD is much better. It is better by a factor of about 2 to 3. The low checkpoint residuals prove the high geometric quality of the UltraCamD camera system. In addition to the quality of the camera system, the other factors that need to be taken into consideration when comparing the two systems are: The distribution of GCPs is much better for UltraCamD block and the overlap is not ideal for Pictometry block.

\subsubsection{Oblique Pictometry Images Block}

The oblique Pictometry block consists of 57 oblique aerial photographs (photographs taken with the camera axis points between the horizontal and vertical): 12 of them looking East, 15 looking West, 15 looking North, and 15 looking South. For this block, the images are in the range of only 31 control points. Nine points were used as ground control points and 22 as check control points for the first two AT 
solutions while all control points were used as check points for the third and fourth AT solutions. Fig. 4 depicts the imagery footprints after the performance of AT.

The results of AT for the oblique block are given in Table 3. The results show good image residuals and fit on the ground control points. Again, the RMS of CCPs shows the realistic value of what can be achieved in mapping. Including the additional parameters in float and constrained solutions gave a big improvement for the total image RMSE (10\% to $20 \%$ ) and a slight improvement for CCPs RMS. The use of AP (additional parameters) model improved the
RMS of CCPs significantly which implies the possible existence of systematic errors before applying the additional parameters. It improved the results by a factor of 2 to 3; the biggest accuracy gain was in the height which jumped from $78 \mathrm{~cm}$ to $28 \mathrm{~cm}$.

3.2.4 Combined UltraCamD and Pictometry Imagery Block

This block consists of two blocks: the UltraCamD images block and the oblique Pictometry images block. It comprises 143 images, of which 86 are UltraCamD images and the remaining 57 images are oblique Pictometry images. The number of points that were used as ground control points is 9 and the number of

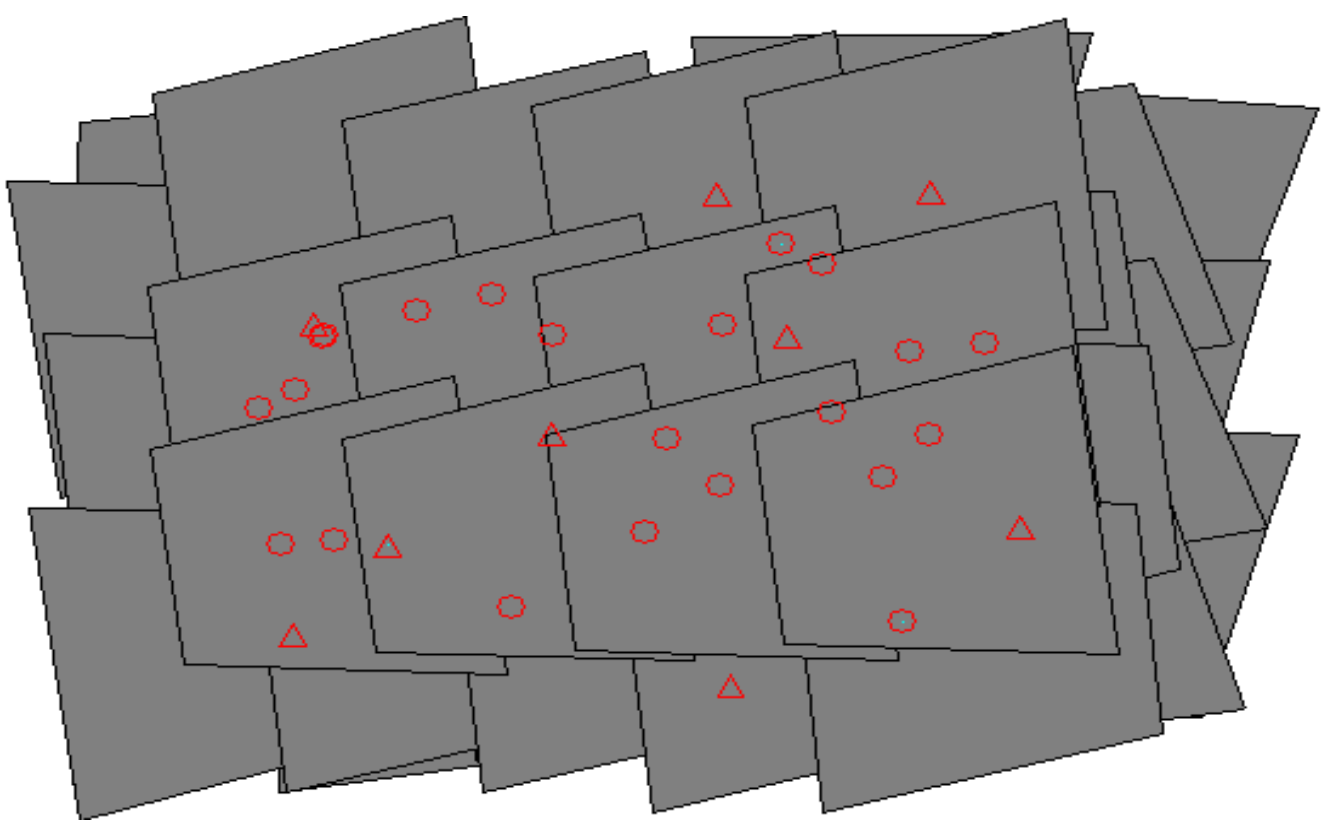

Fig. 4 Oblique images footprint after performing AT.

Table 3 Results of AT for oblique images block using four different solutions.

\begin{tabular}{|c|c|c|c|c|c|c|c|c|c|}
\hline \multicolumn{2}{|l|}{ Solution } & \multicolumn{2}{|c|}{ Float } & \multicolumn{2}{|c|}{ Constrained } & \multicolumn{2}{|c|}{ Integrated } & \multicolumn{2}{|c|}{ DG } \\
\hline \multicolumn{2}{|c|}{ Additional Parameters } & No & Yes & No & Yes & No & Yes & No & Yes \\
\hline \multicolumn{2}{|c|}{ Total image RMSE $(\mu \mathrm{m})$} & 3.8 & 3.2 & 4.2 & 3.4 & 4.9 & 4.0 & 10.0 & 5.5 \\
\hline \multirow{3}{*}{$\begin{array}{l}\text { GCPs RMS } \\
\text { (no.pts) }\end{array}$} & $\mathrm{X}(\mathrm{m})$ & $\begin{array}{l}0.030 \\
(9)\end{array}$ & $\begin{array}{l}0.021 \\
(9)\end{array}$ & $\begin{array}{l}0.056 \\
(9)\end{array}$ & $\begin{array}{l}0.025 \\
(9)\end{array}$ & - & - & - & - \\
\hline & $\mathrm{Y}(\mathrm{m})$ & $\begin{array}{l}0.061 \\
(9)\end{array}$ & $\begin{array}{l}0.050 \\
(9)\end{array}$ & $\begin{array}{l}0.093 \\
(9)\end{array}$ & $\begin{array}{l}0.060 \\
(9)\end{array}$ & - & - & - & - \\
\hline & $\mathrm{Z}(\mathrm{m})$ & $\begin{array}{l}0.066 \\
(9)\end{array}$ & $\begin{array}{l}0.027 \\
(9)\end{array}$ & $\begin{array}{l}0.053 \\
(9)\end{array}$ & $\begin{array}{l}0.023 \\
(9)\end{array}$ & - & - & - & - \\
\hline \multirow{3}{*}{$\begin{array}{l}\text { CCPs RMS } \\
\text { (no.pts) }\end{array}$} & $\mathrm{X}(\mathrm{m})$ & $\begin{array}{l}0.159 \\
(22)\end{array}$ & $\begin{array}{l}0.142 \\
(22)\end{array}$ & $\begin{array}{l}0.160 \\
(22)\end{array}$ & $\begin{array}{l}0.144 \\
(22)\end{array}$ & $\begin{array}{l}0.625 \\
(31)\end{array}$ & $\begin{array}{l}0.240 \\
(31)\end{array}$ & $\begin{array}{l}0.348 \\
(31)\end{array}$ & $\begin{array}{l}0.339 \\
(31)\end{array}$ \\
\hline & $\mathrm{Y}(\mathrm{m})$ & $\begin{array}{l}0.187 \\
(22)\end{array}$ & $\begin{array}{l}0.181 \\
(22)\end{array}$ & $\begin{array}{l}0.192 \\
(22)\end{array}$ & $\begin{array}{l}0.172 \\
(22)\end{array}$ & $\begin{array}{l}0.398 \\
(31)\end{array}$ & $\begin{array}{l}0.169 \\
(31)\end{array}$ & $\begin{array}{l}2.957 \\
(31)\end{array}$ & $\begin{array}{l}2.282 \\
(31)\end{array}$ \\
\hline & $\mathrm{Z}(\mathrm{m})$ & $\begin{array}{l}0.113 \\
(22)\end{array}$ & $\begin{array}{l}0.076 \\
(22)\end{array}$ & $\begin{array}{l}0.086 \\
(22)\end{array}$ & $\begin{array}{l}0.071 \\
(22)\end{array}$ & $\begin{array}{l}0.781 \\
(31)\end{array}$ & $\begin{array}{l}0.286 \\
(31)\end{array}$ & $\begin{array}{l}0.803 \\
(31)\end{array}$ & $\begin{array}{l}0.567 \\
(31)\end{array}$ \\
\hline
\end{tabular}


points used as check control points is 30. The distribution of the tie points and control/check points is shown in Fig. 5 as well as the images projection centres and the camera X-axis while Fig. 6 depicts the images footprint after the performance of AT. The DG solution was not possible in this block because when the EOP set as fixed values, the graphical display function in LPS shows each type of images as one cluster that has the same projection centre (i.e. one cluster of UltraCamD images, and one cluster from each direction of oblique images). In addition, it shows the GCPs, CCPs, and tie points far away from UltraCamD images which should be exactly on top of them as they are vertical images.

The reason behind this might be related to the number of cameras used and the different types of them. Furthermore, there are different flying heights between the two sorties. In addition to that, the quality of the EOP of Pictometry camera system is not known so when setting them as fixed values, they affect the solution. Finally, the software itself could be the reason; it may not support the situation of different cameras with different flying heights as well as setting EOP to fixed values. The results of AT trials are shown in Table 4. The results show good image residuals (about one third of a pixel) and fit on the ground control points. Including the additional parameters in float and constrained solutions gave a little improvement for the total image RMSE and a big

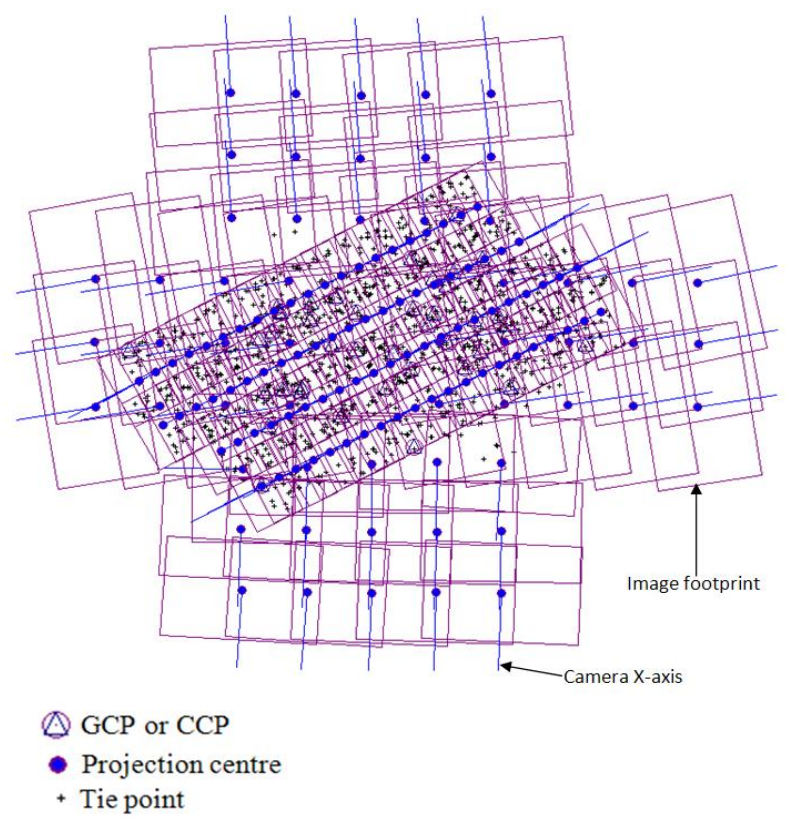

Fig. 5 Distribution of the tie points and control/check points as well as the images projection centres and the camera $\mathrm{X}$-axis of the combined UltraCamD and oblique Pictometry images block.

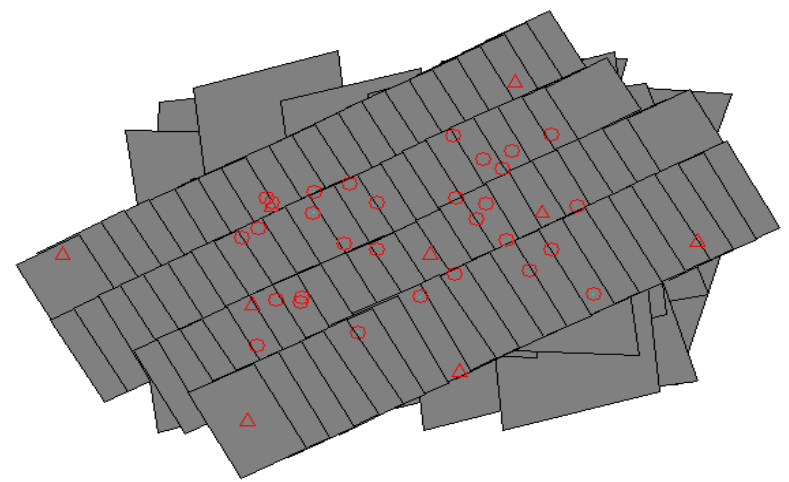

Fig. 6 The combined UltraCamD and oblique Pictometry images footprint after performing AT.

Table 4 AT results of the combined UltraCamD and oblique images block.

\begin{tabular}{|c|c|c|c|c|c|c|c|}
\hline \multirow{2}{*}{\multicolumn{2}{|c|}{$\begin{array}{l}\text { Solution } \\
\text { Additional Parameters }\end{array}$}} & \multicolumn{2}{|c|}{ Float } & \multicolumn{2}{|c|}{ Constrained } & \multicolumn{2}{|c|}{ Integrated } \\
\hline & & No & Yes & No & Yes & No & Yes \\
\hline Total RMSE & & 3.4 & 3.3 & 3.5 & 3.4 & 3.5 & 3.1 \\
\hline \multirow{3}{*}{$\begin{array}{l}\text { GCPs RMS } \\
\text { (no.pts) }\end{array}$} & $\mathrm{X}(\mathrm{m})$ & $\begin{array}{l}0.074 \\
(9)\end{array}$ & $\begin{array}{l}0.080 \\
(9)\end{array}$ & $\begin{array}{l}0.087 \\
(9)\end{array}$ & $\begin{array}{l}0.092 \\
(9)\end{array}$ & - & - \\
\hline & $\mathrm{Y}(\mathrm{m})$ & $\begin{array}{l}0.055 \\
(9)\end{array}$ & $\begin{array}{l}0.051 \\
(9)\end{array}$ & $\begin{array}{l}0.051 \\
(9)\end{array}$ & $\begin{array}{l}0.049 \\
(9)\end{array}$ & - & - \\
\hline & $\mathrm{Z}(\mathrm{m})$ & $\begin{array}{l}0.052 \\
(9)\end{array}$ & $\begin{array}{c}0.035 \\
(9)\end{array}$ & $\begin{array}{l}0.056 \\
(9)\end{array}$ & $\begin{array}{l}0.030 \\
(9)\end{array}$ & - & - \\
\hline \multirow{3}{*}{$\begin{array}{l}\text { CCPs RMS } \\
\text { (no.pts) }\end{array}$} & $X(m)$ & $\begin{array}{l}0.075 \\
(30)\end{array}$ & $\begin{array}{l}0.074 \\
(30)\end{array}$ & $\begin{array}{l}0.096 \\
(30)\end{array}$ & $\begin{array}{l}0.095 \\
(30)\end{array}$ & $\begin{array}{l}0.442 \\
(39)\end{array}$ & $\begin{array}{l}0.158 \\
(39)\end{array}$ \\
\hline & $\mathrm{Y}(\mathrm{m})$ & $\begin{array}{l}0.076 \\
(30)\end{array}$ & $\begin{array}{l}0.072 \\
(30)\end{array}$ & $\begin{array}{l}0.083 \\
(30)\end{array}$ & $\begin{array}{l}0.081 \\
(30)\end{array}$ & $\begin{array}{l}0.226 \\
(39)\end{array}$ & $\begin{array}{l}0.198 \\
(39)\end{array}$ \\
\hline & $\mathrm{Z}(\mathrm{m})$ & $\begin{array}{l}0.091 \\
(30)\end{array}$ & $\begin{array}{l}0.109 \\
(30)\end{array}$ & $\begin{array}{l}0.103 \\
(30)\end{array}$ & $\begin{array}{l}0.080 \\
(30)\end{array}$ & $\begin{array}{l}0.212 \\
(39)\end{array}$ & $\begin{array}{l}0.275 \\
(39)\end{array}$ \\
\hline
\end{tabular}


improvement for the height component of GCPs. With regard to the integrated solution, the use of AP model improved the RMS of CCPs significantly in $\mathrm{X}$-direction (improvement of about 65\%) and improved the Y-component slightly. On the other hand, the height accuracy was better before applying the additional parameters.

\subsection{Modelling Results}

Building modelling using aerial photos requires different processes which can be summarised as following [4]:

(1) Extraction of 3D geometry of buildings using the roof outlines;

(2) Extrusion of the digitised polygons of each building as a whole;

(3) Texturing the 3D models using different techniques.

\subsubsection{Extraction of 3D Geometry}

The 3D building reconstruction is a difficult problem, mainly due to the complexity of the buildings. The success of automation in this field depends on many factors and is a hot topic in research [5].

For efficient building modelling, it is preferable to first digitize all the small roof details (dormers, chimneys, ventilation equipment etc.) using 3D polygons and then digitize the main roof outline as a separate polygon. In order to create the building facades, all the roof polygons then should be extruded onto the ground level to create the polyhedral model. Extrusion turns points into vertical lines, lines into walls, and polygons into blocks. Extraction of 3D geometry for all buildings in both study areas has been performed using vertical Pictometry imagery block. The UltraCamD block was used to extract the 3D geometry for only the University campus test site. Extraction of 3D geometry from the oblique images was not possible because some roof outlines cannot be seen due to the tilt of the oblique images. However, the availability of oblique imagery during digitization provided additional information for the interpretation of geometry by allowing each building to be seen from different angles. Oblique images were of a great benefit in helping the interpretation of building outlines where differences in building height required digitizing of separate polygons. Overall, the level of detail for the 3D models derived from the Pictometry images block is comparable with the level of detail acquired from the UltraCamD images block bearing in mind that the scale of Pictometry images, although it is suitable for extraction of 3D building geometry with some fine details, is much smaller than that of UltraCamD images.

3.3.2 Accuracy of 3D Models Extracted from Pictometry Imagery

The 3D building polygons extracted from Pictometry imagery will be compared with the BM (benchmark) polygons (extracted from UltraCamD) qualitatively and quantitatively. The qualitative evaluation includes a visual comparison between the reconstructed buildings from the vertical Pictometry imagery and the BM building models. This comparison will provide a useful indication of the overall quality. The qualitative comparison for some of the reconstructed buildings in the University main park is given in Fig. 7.

For the quantitative evaluation of the Pictometry 3D models, a planimetric and height accuracy was compared with the BM models (as shown in Fig. 8). Table 5 shows a summary of the results achieved from comparing 977 points on 99 buildings in plan (X and $\mathrm{Y}$ components). It also shows the results of comparing 762 points on 100 buildings in height ( $\mathrm{Z}$ component). From the results in Table 5, the GSD and the flying height between the two camera systems must be taken into consideration. The Pictometry imagery has produced good results especially in $\mathrm{X}$ and $\mathrm{Y}$ taking into consideration the differences in resolution.

\subsection{Texturing Results}

Adding texture to the building models created is 


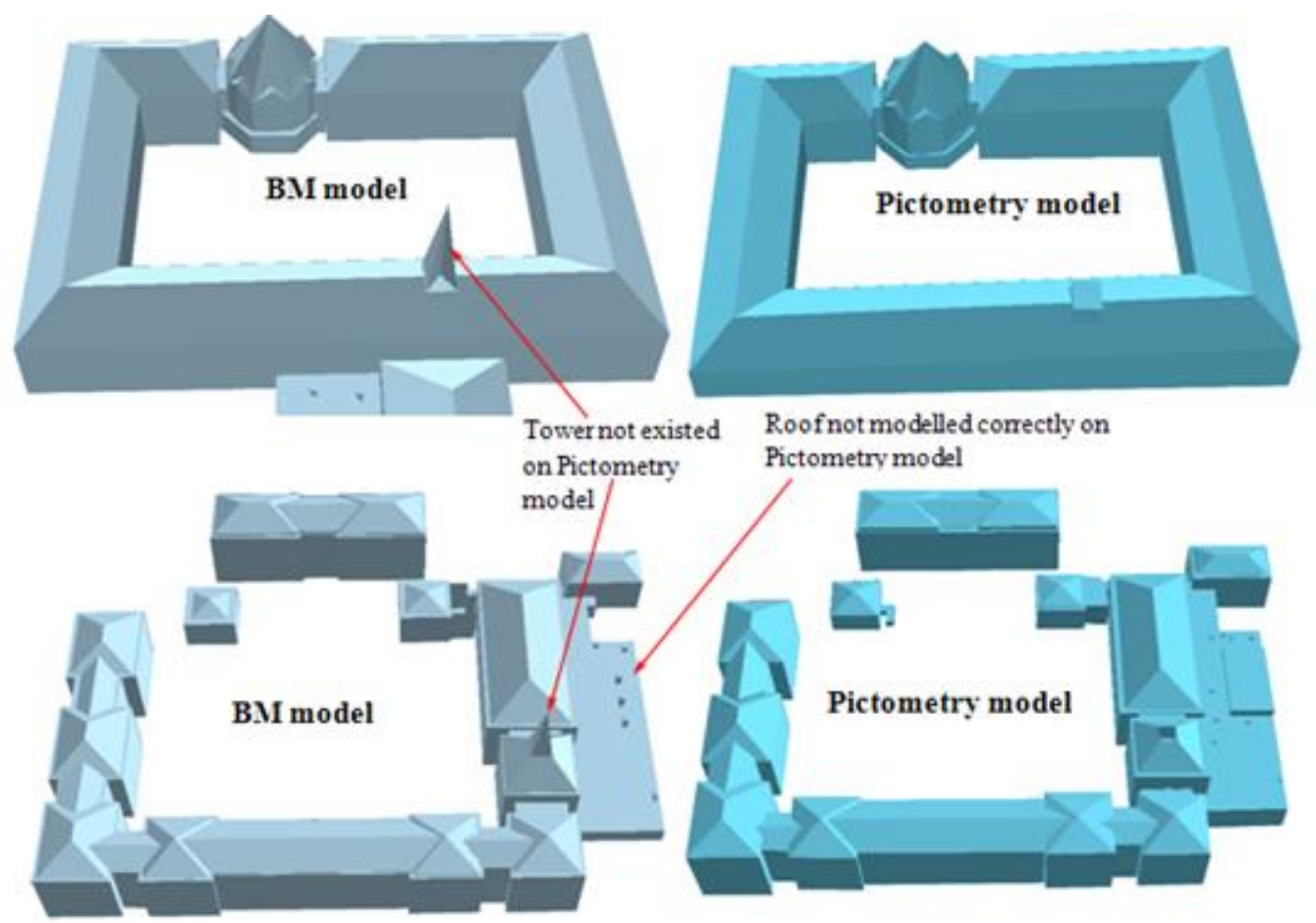

Fig. 7 Qualitative comparison between the UltraCamD 3D models (BM) and the vertical Pictometry 3D models for Nottingham University main campus.

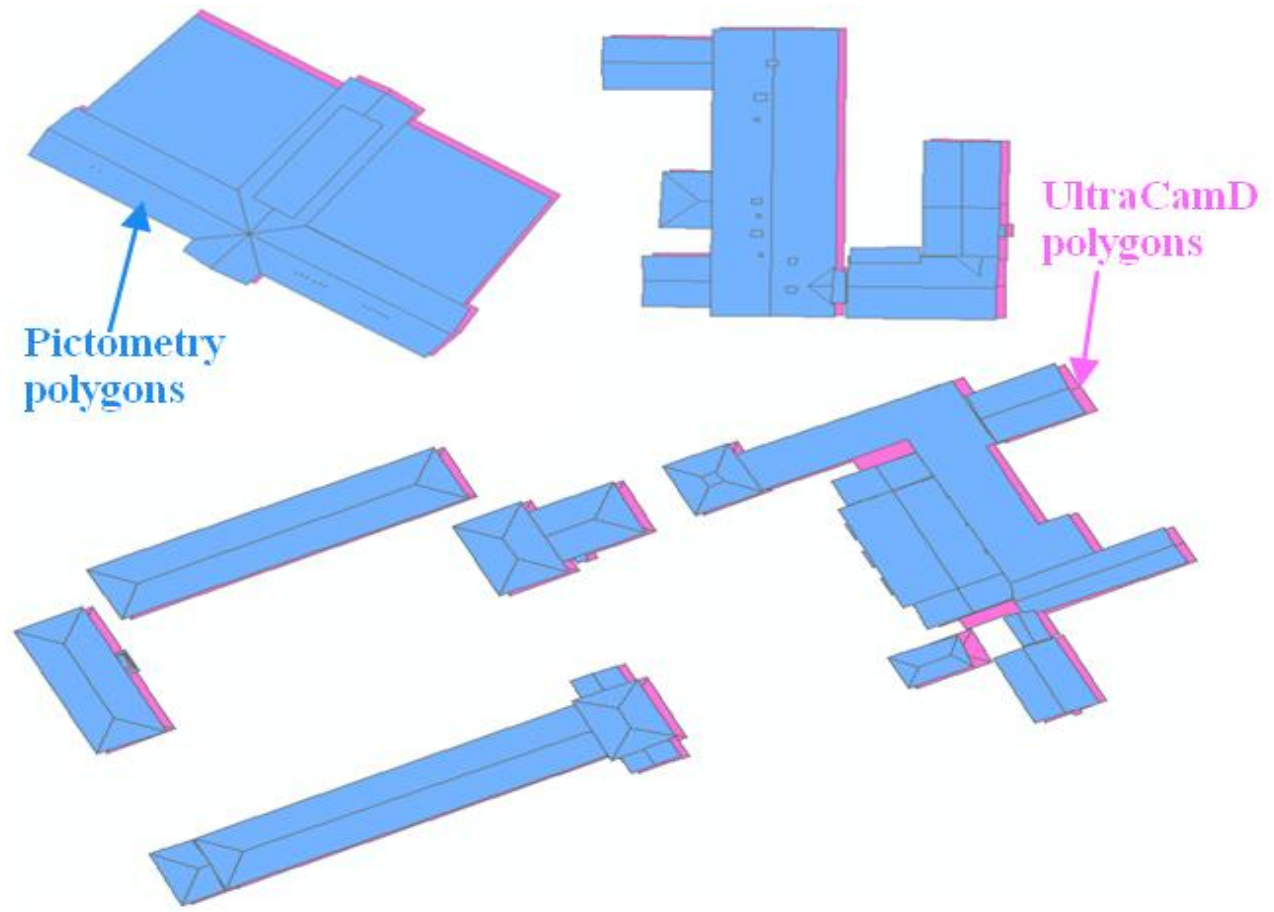

Fig. 8 Two roof outlines imposed over each other to be used for Planimetric comparison.

important since it makes 3D models more realistic. Texturing of the 3D polygons was performed using the vertical Pictometry block, oblique Pictometry block, UltraCamD block, a combined (vertical and oblique) Pictometry block, and a combined UltraCamD and Pictometry block. The visual inspection of the textured models shows that using either vertical Pictometry block or UltraCamD block 
has given very good roof structure but when it comes to facade texturing the quality was not as good as roofs quality, the texture quality of the building facades is considerably degraded. When only the block of oblique images was used for texturing the 3D models, the facade texturing was of very good quality but the texturing quality of some buildings' roofs was reduced compared with the vertical images (as shown in Fig. 9). Combining both vertical and oblique images gives the benefit of good quality textures for both the roofs and facades (as shown in Fig. 10).

The overall quality of the Pictometry images is characterized in some instances by the presence of haze which affects the texture mapping quality (as shown in Fig. 11). Fig. 12 shows the effect of area that cannot be seen from the aerial images due to shadow or perspective view often called "dead ground".

Fig. 12 also shows a building with internal quadrangles which are very challenging to texture from airborne images.

Table 5 Results of quantitative evaluation of 3D polygons extracted from Pictometry and UltraCamD.

\begin{tabular}{llll}
\hline Component & $\mathrm{X}$ & $\mathrm{Y}$ & Avg. Z \\
\hline Min. & -0.960 & -0.800 & -2.380 \\
Max. & 0.582 & 0.590 & 2.300 \\
St.dev. & 0.286 & 0.187 & 0.952 \\
\hline
\end{tabular}

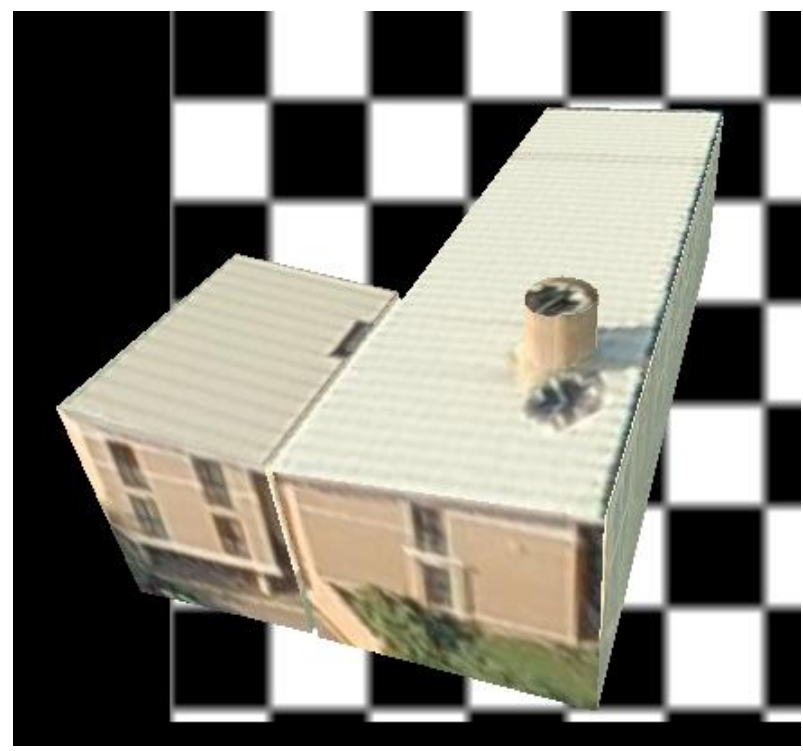

Fig. 9 3D building model textured using Pictometry oblique images block.

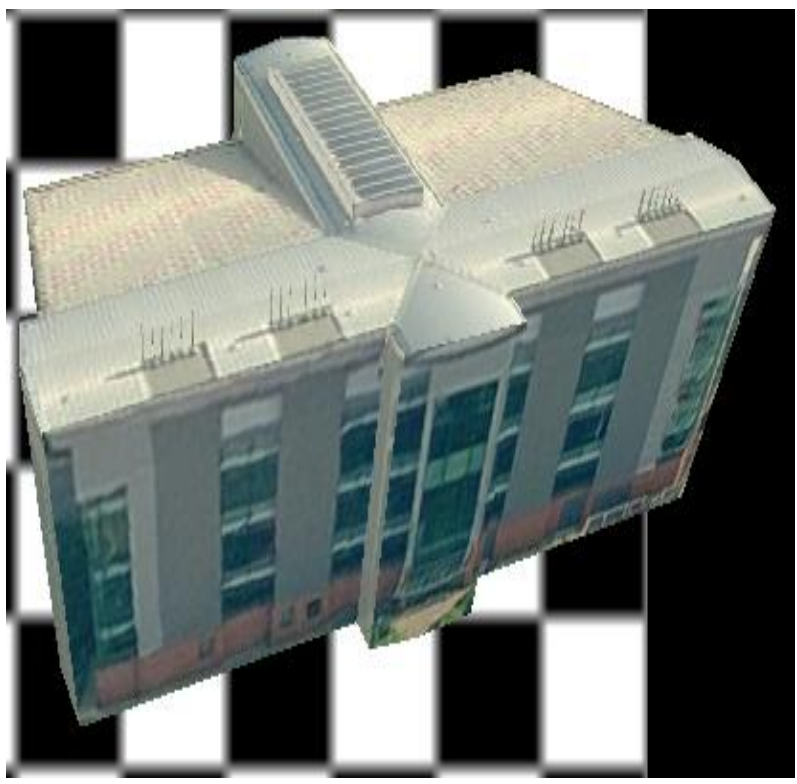

Fig. 10 3D building model textured using Pictometry combined block.

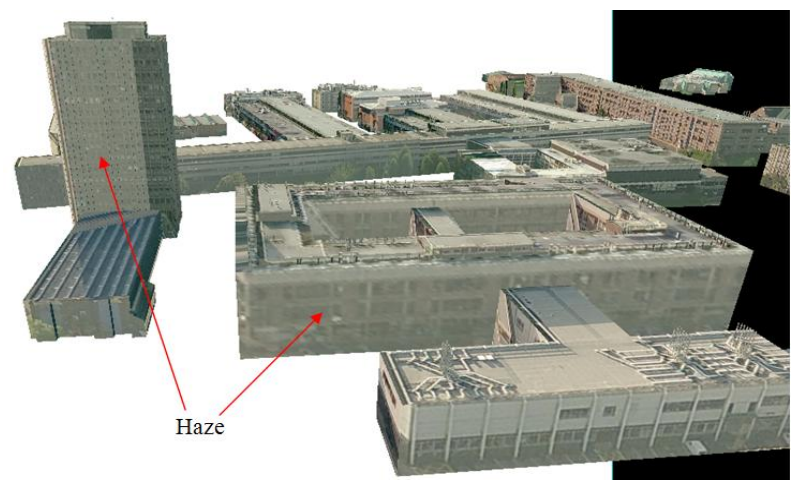

Fig. 11 Texturing quality is affected by haze in some images.

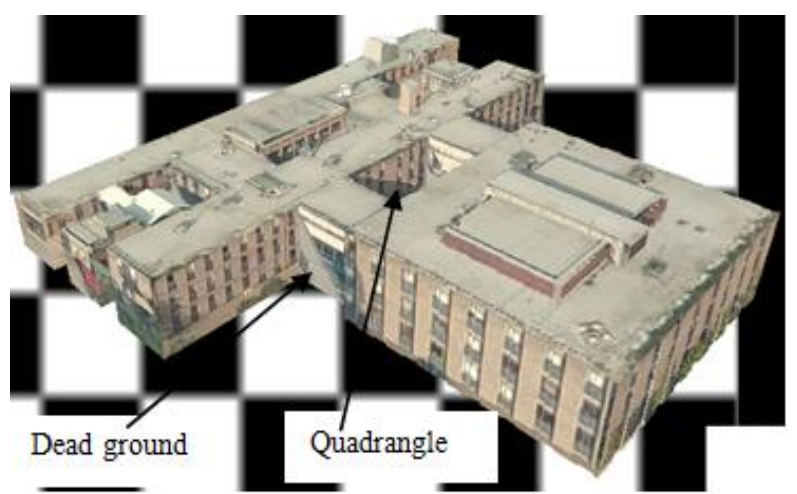

Fig. 12 Texturing quality is aaffected by dead ground in some images.

Occlusions can occur often due to vegetation or dynamic objects (e.g. moving people or vehicles). Modelling these objects and the buildings behind correctly is often complex or time-consuming. This 
can only really be overcome by the use of terrestrial images behind the vegetation although it is a very time-consuming process particularly in large modelling projects [6] or using patches of the visible facade to paste over the obscured surface. The integration of terrestrial image of any building facade with the combined aerial imagery block has been successfully and automatically performed [7]. This allows for automatically using terrestrial images in texturing which significantly enhances the facades and at the same time is faster, cheaper, more accurate, and easier to implement.

\section{Conclusion}

The use of combined blocks of vertical and oblique images in AT showed that good point coordination can be achieved. The point coordination in AT can come from not just an intersection of a pair of image point's rays but also from multiple rays. The coordination quality is further improved by the use of oblique images providing strong intersection angles at the measured points [8]. The check points show more realistic values of what might be achievable for mapping.

Special care was given to the integrated sensor orientation and DG solutions as using these solutions compared to conventional photogrammetry demonstrates a significant decrease in time and thus cost for photogrammetric processes because the use of automatically measured tie points is a cost effective way of generating ground control points. The results of direct sensor orientation have shown that height accuracy of $0.06 \%$ of flying height and plan accuracy of $0.02 \%$ of flying height can be achieved for the vertical Pictometry images block. Combining of oblique images with vertical images in one block has given a very good improvement for the height quality which reached $0.02 \%$ of flying height.

To ensure that all building facades and roof tops in an area are covered and properly textured, it is necessary to utilize multiple oblique and vertical aerial images with different viewing angles. Thus, using the combined UltraCamD and oblique images block or the combined vertical and oblique Pictometry images block gave high texture quality for both facades and rooftops.

The results show that the revolutionary Pictometry oblique imagery can be used for texture mapping of large models quickly and can enable photorealism.

Terrestrial imagery might be combined with oblique imagery in certain areas to give better quality models, particularly when ground level viewing of the models is required.

\section{Acknowledgment}

The author would like to thank Blom Aerofilms Limited for providing the aerial photography of the test sites.

\section{References}

[1] Gruen, A. 2000. "Semi-Automated Approaches to Site Recording and Modelling." International Archives of Photogrammetry and Remote Sensing XXXIII: 309-18.

[2] Tunc, E., Karsli, F., and Ayhan, E. 2004. "3D City Reconstruction by Different Technologies to Manage and Reorganize the Current Situation." International Society for Photogrammetry and Remote Sensing Congress.

[3] Lerma, J. L., Vidal, J. S., and Portale, S. C. 2004 "Three-Dimensionalcity Model Visualization for Real Time Guided Museum Tours." The Photogrammetric Record 19 (108): 360-74.

[4] Smith, M., Hamruni, A., and Jamieson, A. 2009. “3D Urban Modelling Using Airborne Oblique and Vertical Imagery." ISPRS Hannover Workshop 2009. The International Archives of the Photogrammetry, Remote Sensing and Spatial Information Sciences, Vol. 34, Part XXX. Hannover, Germany.

[5] Ortin, D., and Remondino, F. 2008. "Occlusion-Free Image Generation for Realistic Texture Mapping.” ISPRS Congress Beijing 2008. Beijing, The International Archives of the Photogrammetry, Remote Sensing and Spatial Information Sciences.

[6] Meng, L., and Forberg, A. 2007. "3D Building Generalisation." In Challenges in the Portrayal of Geographic Information: Issues of Generalisation and Multi Scale Representation, edited by Mackaness, W., Ruas, A., and Sarjakoski, T. Amesterdam: Elsevier 
Science Ltd.

[7] Hamruni, A., and Smith, M. 2013. "Automatic Integration of Terrestrial and Oblique Images in 3D Modelling." In Proceedings of the RSPSoc Annual
Conference, Earth Observation for Problem Solving.

[8] Hamruni, A., Smith M., and Jamieson, A. 2008. "Investigation into the geometry of Pictometry imagery." RSPSoc annual conference. Falmouth, UK. 